\title{
DOSSIÊ PRÉ-MODERNISMOS
}

Pensares em Revista, n. 1 (jul/dez 2012)

\section{APRESENTAÇÃO}

Desde pelo menos a década de 1980 - com o aparecimento da importante coletânea Sobre o pré-modernismo (1988), publicada pela Fundação Casa de Rui Barbosa - já era consenso entre os pesquisadores da área de que o termo "prémodernismo" não servia para descrever a literatura brasileira das décadas de 1890 a, digamos, 1930. A denominação se limitava a conceituar um período a partir daquele que o seguia (o que era um anacronismo), demarcava em 1922 um ano zero da modernidade brasileira, chamando de "pré" o período imediatamente anterior, cuja identidade era então sequestrada. $\mathrm{O}$ uso do termo (que persiste na maior parte dos manuais escolares) seria a marca de uma historiografia que poderíamos chamar de "modernista", já que usava legitimamente o modernismo paulista (suas teorias, porta-vozes, posicionamentos e tradições) como plataforma da qual lia e ordenava a literatura brasileira anterior e posterior a 1922. O fato de que esta historiografia ainda vigora nos manuais (promovendo a difusão de um senso comum sobre o que é a literatura brasileira que ainda domina parte dos cursos de Letras) é prova de quão bem-sucedida foi a refundação modernista.

Dizemos que o chamado "pré-modernismo" vai até 1930 (e não até 1922, como às vezes aparece na historiografia) porque o acontecimento da Semana de Arte Moderna como divisor de águas na história da literatura brasileira é uma superestimação. Sabemos que as estéticas e os hábitos culturais são sistemas de longa duração que não se transformam rapidamente ou em datas precisas. Mesmo assim - considerando que tais demarcações são artificiais -, poderíamos pensar numa temporalidade de mais ou menos quarenta anos, digamos, de 1890 a 1930, que corresponderia no Brasil (e especialmente no Rio de Janeiro) a uma experiência histórica nova, essencialmente moderna, relacionada mais ou menos com o que a historiografia chama de República Velha, Primeira República ou Belle Époque. Reivindicar a modernidade da literatura do 
período, conhecê-la e estudá-la, nos parece essencial para o que poderíamos chamar de uma historiografia literária "pós-modernista" - um termo que também é inadequado, mas que serve por ora para demarcar um afastamento do paradigma (ainda) dominante.

Insistimos na relativização do "mais ou menos" porque a modernidade que queremos associar à literatura da Belle Époque já vinha se configurando desde a década de 1870, logo após o fim da Guerra do Paraguai (1864-1870) - evento que marca o começo do declínio do Brasil imperial, de seus produtos culturais e aparelhos ideológicos. As duas últimas décadas do século XIX assistiriam a uma aceleração desta modernização, com o crescimento da imprensa, das cidades, das casas editoriais e do público leitor (Cf. EL FAR, 2004; MARTINS \& DE LUCA, 2011), dos serviços de comunicação e transportes, assim como a radicalização da campanha abolicionista - o primeiro movimento de massa da história do Brasil (Cf. MACHADO, 1994), o fim da escravidão em maio de 1888 e a deposição do imperador em novembro de 1889 eventos que contavam com a adesão da maior parte da população, especialmente das cidades, sugerindo que havia uma "desafeição" ao regime imperial, maior do que a afeição da população ao monarca (Cf. MELLO, 2007).

A década de 1890 trouxe os paradoxos da desconstrução da velha ordem, o confronto dos que tiveram seus interesses lesados com seu fim, assim como daqueles que simplesmente simpatizavam com ela (entre os quais havia ex-escravos), e ainda daqueles (como parte dos homens de letras) que julgavam a república que se instalara uma sombra pálida do projeto (essencialmente descentralizador e libertário) pelo qual haviam lutado na imprensa, na literatura, e nos movimentos sociais. Foi um período de instabilidade jurídica e monetária, de sedições intra-elite (como a Revolta da Armada em 1893), estados de sítio na capital, repressão à imprensa e aos intelectuais, e até atentados, como a tentativa de assassinato de Prudente de Morais (1841-1902) em novembro de 1897, para não falarmos da Revolução Federalista no Rio Grande do Sul (1893-1895) e da Guerra de Canudos (1896-1897), na Bahia. No final da década de 1890 havia, afinal, um projeto vencedor, capitaneado pelos cafeicultores paulistas. Este consenso conheceria um período de estabilidade relativa e se sustentaria, por lógicas internas e externas, até mais ou menos o final da década de 1920.

A literatura brasileira da Belle Époque foi a literatura da modernidade desordenada da civilização pós-Brasil imperial. A modernidade (embora pudesse contê- 
los) não deve ser entendida como sinônimo de ordem e/ou progresso (Cf. CALINESCU, 1987; COMPAGNON, 1999; TOURAINE, 1999), ainda que houvesse, ao menos para a população do Rio de Janeiro, uma experiência de "aceleração do ritmo de vida", já na década de 1880 (MELLO, 2007, p. 14). A experiência específica da modernidade europeia do século XIX não precisa servir de parâmetro nem deveria ser alçada à categoria de modernidade ideal, em relação a qual outras experiências de modernidade são julgadas menos ou mais autênticas. O que se configurava, desde 1880, era uma experiência de modernidade desordenada que mudava as regras do jogo e ampliava o “espaço dos possíveis” (Cf. BOURDIEU, 1996) da atividade literária. Aos organizadores deste dossiê interessa ler as valiosas contribuições enviadas tendo este cenário como pano de fundo. Chamamo-lo ironicamente de "Pré-Modernismos" para sugerir narrativas historiográficas alternativas sobre um período ainda mal compreendido da literatura brasileira, a despeito dos avanços dos últimos trinta anos.

Em "Euclides da Cunha e a poesia do pensamento", Anélia Pietrani, reconhecendo em A geopoética de Euclides da Cunha (2009), de Ronaldes de Melo e Souza, um estudo precursor, descreve um projeto de escrita que não compartimentalizava a ciência e a arte. A autora imagina Euclides como um escritor-viajante que leva em si um pouco do caminhante solitário de Rousseau e um pouco do flâneur de Baudelaire. O olhar busca a natureza (não a paisagem), mas a natureza do homem e da luta. Se há uma cartografia em Os sertões, trata-se da cartografia interior do sujeito que pensa sobre si mesmo para pensar sobre o mundo. Daí a irrupção na narrativa de terceira pessoa, afeita à impessoalidade realista, de um "eu" que analisa, opina e critica, pondo sob suspeição a imparcialidade científica e sob tensão o ato de narrar, conforme exemplos diligentemente apresentados pela autora.

Regina Simon Silva, em "A história de Canudos narrada como drama”, parte do debate em torno do status epistemológico da narrativa historiográfica para explorar as fronteiras entre história e literatura em Os sertões. A autora toma as reportagens escritas por Euclides da Cunha para o jornal O Estado de São Paulo como "roteiro" ou "matéria-prima" de Os sertões. As reportagens, que têm interesse por si mesmas, revelam as condições de produção da própria escrita, assim como expressam dúvidas sobre o lugar da eloquência nos gêneros jornalísticos. Euclides teria percebido e explorado o potencial trágico da campanha de Canudos já na redação das reportagens, 
valendo-se de recursos e estratégias da tradição literária com o intuito de amplificar o fato histórico. Por ocasião da redação de Os sertões, a narrativa, intencionalmente ou não, assumia uma dimensão dramática que teatralizava a história de Canudos, dividida em três partes, como sugere a autora: "terra/cenário; homem/personagens; luta/atuação dos atores". Neste drama se destaca o personagem ambíguo do sertanejo, quase sempre tratado como figura coletiva, ao mesmo tempo frágil e forte, "desengonçado" e ágil na luta.

Em “O mal-estar de Isaías: a crise do romance em Lima Barreto", Carmem Lúcia Negreiros de Figueiredo apresenta uma faceta menos conhecida do escritor carioca: a de crítico da linguagem (e do gênero romanesco) como suficiente para transcrever a experiência do sujeito moderno. Tomando o romance Recordações do escrivão Isaías Caminha (1907) como objeto de estudo, a autora discute os modos como a obra rejeita a "escrita triunfal", tradicionalmente associada ao gênero épico e ao romance realista do século XIX. No romance, o foco na luta íntima do protagonista (e não no mundo da ação social) subjetiva o tempo da narrativa, que se desenvolve ilogicamente, entrecruzando temporalidades por meio de lacunas e recuos. $\mathrm{O}$ ato de narrar se transforma num processo de "montagem e justaposição de vozes", que se verifica em toda a obra, inclusive no prefácio - evidência de uma "forte consciência metaficcional" em Lima Barreto, sobre o ato de narrar.

No ensaio "Lima Barreto e o viés do realismo popular na literatura brasileira", Maria Cristina Batalha sugere que a obra do escritor carioca representa um retorno a uma tradição realista da literatura brasileira que remete ao romance Memórias de um sargento de milícias (1852), de Manuel Antônio de Almeida (1831-1861). A autora mostra como a ficção de Lima Barreto apostava no modelo de incorporação da cultura suburbana e da estética popular (na adoção de recursos da escrita folhetinesca), em contraste com os modernistas, que buscavam o que se designava então como "genuíno" e "primitivo" na cultura brasileira, tais como o índio, o folclore africano e sertanejo. Ao considerar a cultura dos subúrbios das grandes cidades como contribuição legítima a um projeto de nação, Lima Barreto trazia à literatura o ponto de vista dos excluídos. Isso se operava no plano estético pela ambiguidade do ponto de vista do narrador, assim como pelo afastamento da linguagem academicista e pela opção por uma linguagem simples e 
despojada, buscando integrar leitores marginalizados pelo hermetismo em que o movimento modernista muitas vezes se encerraria.

Rosa Gens, em "Retratos em cantoneiras: imagens do Rio de Janeiro Belle Époque em João do Rio e Lima Barreto", toma os dois escritores como cronistas privilegiados do processo de redimensionamento de ocupação do espaço urbano na capital nas duas primeiras décadas do século XX. A autora aponta que a Belle Époque foi um período de mudanças e transformações profundas, e de intensa vida cultural. João do Rio e Lima Barreto (que tinham a mesma idade) tomavam o "estrambótico" Rio de Janeiro não como pano de fundo, mas como o próprio tema de suas obras. Apesar de "flanar" por todos os espaços, centrais e periféricos, João do Rio, como sugere a autora, vislumbrava uma cidade mais civilizada do que Lima, que era mais crítico do processo de modernização, cuja face violenta e excludente destacava em seus escritos. Na leitura de A alma encantadora das ruas (1908), de João do Rio, e Vida e morte de M. J. Gonzaga de Sá (1919), de Lima, obras privilegiadas pela autora, encontramos o retrato do Rio de Janeiro como "grande cidade", bela e confusa, com encantos e misérias, ao mesmo tempo cosmopolita e provinciana.

Por meio da leitura de três escritores ilustres do período: Olavo Bilac (1865-1918), João do Rio e Lima Barreto, Sophia Beal, em "A conquista das trevas na literatura prémodernista", acompanha o debate sobre as reformas urbanas do Rio de Janeiro nas primeiras décadas do século XX, tendo como foco de interesse a expansão da iluminação elétrica nas ruas da cidade. Os postes de luz elétrica da capital, como sugere a autora, atuavam como "sinédoque de uma modernização ideal". Os escritores recorriam à tensão entre trevas e luz nos textos publicados nos jornais, ecoando ou negando o discurso ufanista oficial, na demarcação de um "antes" e um "depois" das reformas. Enquanto Bilac exaltava a limpeza e o bom gosto da avenida iluminada, Lima Barreto atacava as reformas por promoverem a exclusão social, apontando para as trevas que a luz mal disfarçava. João do Rio nutria um posicionamento ambíguo. Ao mesmo tempo que tinha olhos para a dimensão sensorial e mágica da eletrificação dos espaços públicos, o cronista notava que as reformas urbanas poderiam excluir as classes trabalhadoras dos benefícios da modernização.

No ensaio "Francisco de Assis Barbosa: o repórter que sonhava", Antônio Arnoni estuda as opções intelectuais deste "cronista exemplar da nossa vida literária", que nas 
décadas de 1940-50 organizou e reeditou a obra de Lima Barreto. Para Arnoni, uma das marcas da escrita de Chico Barbosa era o ingresso do repórter nas cenas de seus próprios relatos, que era um modo de reviver o sonho original de escrever ficção. Por isso, ele seria sempre um "repórter dobrado de ficcionista" que buscava compreender o método de criação e a personalidade dos artistas. Na análise do autor ganham destaque alguns escritos de Chico Barbosa, tais como as reportagens sobre Villa-Lobos e Mario de Andrade, que incluíam entrevista, intensa pesquisa e redação primorosa. Mas possivelmente seu maior feito terá sido resgatar Lima Barreto do "limbo" da literatura brasileira, especialmente com a publicação do estudo biográfico A vida de Lima Barreto (1952), que iria definir o modo de inserção do escritor no âmbito da literatura brasileira, ao valorizar sua história de rebeldia e sofrimento.

Jean Marcel Oliveira Araujo, em "O pré-modernismo: a luta entre passadistas, modernos e modernistas no campo artístico brasileiro", propõe mapear as diversas posições assumidas pelos agentes nos debates estéticos das primeiras décadas do século XX. O autor faz um histórico das controvérsias sobre a terminologia e a cronologia do período, que foi chamado de "intervalar" ou de "antecipação estética", podendo começar no final do século XIX e ir até 1925, ou, como ele prefere, de 1902 a 1922. Por meio da leitura de textos de Monteiro Lobato, Olavo Bilac, Mario de Andrade, e principalmente do poema "Os sapos" (1919), de Manuel Bandeira, o autor identifica pelo menos duas posições antagônicas no campo artístico nas duas primeiras décadas do século XX: de um lado os defensores da arte pura, de inspiração clássica (Lobato, Bilac e o parnasianismo), e de outro os defensores da arte impura, anti-academicista e antioficial (Mario de Andrade e Manuel Bandeira). O que havia, como aponta o autor, era uma batalha pelo domínio no campo artístico brasileiro.

Em "Os simbolistas: virando o século", Vera Lins faz um breve histórico da recuperação de escritores do período estigmatizados pelas vanguardas modernistas. Além das revisões já consolidadas de Euclides da Cunha, Lima Barreto e João do Rio, a autora lembra a recuperação, na década de 1960, pelos irmãos Campos, de Sousândrade (1832-1902), Pedro Kilkerry (1885-1917) e ainda Maranhão Sobrinho (1879-1915). A política dos simbolistas era a defesa da autonomia da arte, radicalmente separada do mundo da mercadoria e antirrealista por princípio. Associada ao sentido crepuscular do moderno e bebida em Baudelaire, sua melancolia era alimentada pelo desencanto com a 
república autoritária recém-instalada, assim como pela resistência dos escritores dominantes, como Machado de Assis e José Verissimo, ao grupo. Daí emanariam as imagens de emparedamento da poesia de Cruz e Souza (1861-1898), que falam de "um país bloqueado". Vera Lins destaca dois críticos contemporâneos que apoiavam o movimento simbolista, mas quase não foram ouvidos: Nestor Vitor (1868-1932) e Gonzaga Duque (1863-1911), em cujos escritos a autora detecta um pensamento crítico original e moderno, que problematizava a arte e a cultura brasileiras já na década de 1890.

Cláudio do Carmo Gonçalves, em "Por fora do pré-modernismo", aponta a diversidade estética do pré-modernismo como fator de vigor, e lembra que uma das consequências do alijamento do período foi o esquecimento de uma série de escritores atuantes e de enorme prestígio intelectual à época, como Gustavo Barroso (1888-1959), cuja obra o ensaio se propõe a apresentar. O interesse pela obra de Barroso reside na peculiaridade de seu posicionamento estético, como aponta o autor, que representava um "entre-lugar" entre a adequação e o deslocamento em relação ao cânone da época. O escritor cearense foi um dos muitos intelectuais polígrafos da República Velha, que praticava vários gêneros textuais (romance, conto, ensaio, crônica, historiografia), e para quem a escrita era uma etapa (ou um aspecto) de uma trajetória social e política. Dotados de capital político e cultural, homens de letras como Barroso legitimavam as narrativas simbólicas dominantes sobre o país no início do século, fortalecendo sua condição de intelectual de destaque na sociedade.

Em "O arquivo literário de Adelino Magalhães: muitas possibilidades", Stela de Castro Bichuette debate sobre o trabalho com fontes primárias nos estudos literários e estuda outro escritor esquecido da Belle Époque: Adelino Magalhães (1887-1969). Via Jacques Derrida, a autora lembra que o arquivo designa ao mesmo tempo um lugar onde se guardam documentos e o "guardião" (autoridade) que os ordena e classifica. O trabalho com esse tipo de documentação tem o potencial de criar "novos modelos epistemológicos" para a pesquisa na área, criando alternativas às abordagens imanentistas e/ou historicistas do fato literário. Por meio dos cadernos de memória de Adelino Magalhães, por exemplo, sob a tutela de seus herdeiros, seria possível mapear a atuação do escritor no contexto da vida literária carioca no começo do século XX. Praticamente esquecidos pela historiografia, Adelino Magalhães e outros intelectuais 
ligados a ele, tais como Tasso da Silveira (1895-1968) e Raul Pederneiras (1874-1953), estavam inseridos, como lembra a autora, num debate sobre as novas artes e a modernidade que movimentava a sociedade carioca nos anos de 1920.

Suzane Morais da Veiga, em "Coelho Neto melodramático: estudo dos dramas Ironia (1898) e O dinheiro (1912)", traz um trabalho sobre o mais ilustre dos escritores esquecidos da Belle Époque (e praticamente ignorado pela historiografia): Henrique Coelho Neto (1864-1934). Se já fomos capazes de redimensionar criticamente tantos escritores atuantes do período (como Euclides da Cunha, Lima Barreto, João do Rio, Monteiro Lobato, e até mesmo o Olavo Bilac cronista), ainda estamos devendo isso a Coelho Neto, uma das ausências mais notáveis do compêndio da Casa de Rui. A autora estuda uma faceta praticamente desconhecida do escritor - a de dramaturgo. Para tanto, estuda dois dramas de sua autoria encenados no Rio de Janeiro no período, lidos dentro da tradição do teatro melodramático que na Europa estava ligado, desde o início do século XIX, à ascensão da burguesia e à expansão da arte teatral para plateias sem cultura literária. Em Ironia e $O$ dinheiro, como mostra a autora, Coelho Neto utiliza o imaginário melodramático para compor enredos de forte carga emocional, com dilemas morais que diziam respeito ao cotidiano das classes médias urbanas e do próprio meio teatral.

No estudo "Pré-Modernismo e república: antinomias da Belle Époque no Brasil", Wellington Migliari propõe caminhos para uma revisão mais completa da literatura do período, apresentando um Coelho Neto e um Bilac pouco conhecidos da historiografia, cômicos e críticos da modernização da Belle Époque, assim como da subserviência cultural à França. Os escritores eram de uma geração de intelectuais republicanos que escreviam em liberdade no final do império, mas foram perseguidos na primeira década republicana. Tendo como base as pesquisas do historiador Elias Thomé Saliba, sugere que a representação cômica ou humorística da vida e do mundo era uma maneira de dar sentido a uma realidade sem sentido aparente. $\mathrm{O}$ autor nota que nenhum modelo explicativo disponível sobre o chamado pré-modernismo rompe com a lógica do antes e depois da Semana de Arte Moderna. Em contos e crônicas de Coelho Neto, Artur Azevedo e Olavo Bilac, analisadas pelo autor, encontram-se dúvidas bem-humoradas sobre o universo da cidadania recém-nascida. Desse ponto de vista, sugere o ensaio, 
poderíamos ler a literatura dos chamados pré-modernistas como "a paródia da modernização conservadora" do Brasil pós-imperial.

Fechamos o dossiê com uma saborosa entrevista com a professora Lucia Helena, da Universidade Federal Fluminense, a quem prestamos homenagem no primeiro número da Pensares em revista. Lucia Helena fala sobre sua pesquisa, sua trajetória intelectual, o que anda lendo, sobre o papel do intelectual e o futuro da pesquisa na universidade, assim como sobre o pré-modernismo, Augusto dos Anjos, Euclides da Cunha e Coelho Neto.

\section{Leonardo Mendes \\ Paulo César de Oliveira Organizadores do Dossiê}

\section{Referências bibliográficas:}

BOURDIEU, Pierre. Por uma ciência das obras. Razões práticas. Sobre a teoria da ação. Campinas, SP: Papirus, 1996, p. 53-73.

CALINESCU, Matei. Five faces of modernity. Durham: Duke UP, 1987.

COMPAGNON, Antoine. Os cinco paradoxos da modernidade. Belo Horizonte: Editora UFMG, 1999.

EL FAR, Alessandra. Páginas de sensação. Literatura popular e pornográfica no Rio de Janeiro (1870-1924). São Paulo: Companhia das Letras, 2004.

MACHADO, Maria Helena. O plano e o pânico: os movimentos sociais na década da abolição. Rio de Janeiro: Editora UFRJ, 1994.

MARTINS, Ana Luiza; DE LUCA, Tania Regina (Orgs.). História da imprensa no Brasil. São Paulo: Contexto, 2011.

MELLO, Maria Tereza Chaves de. A república consentida: cultura democrática e científica do final do Império. Rio de Janeiro: Editora FGV, 2007.

TOURAINE, Alain. Crítica da modernidade. Petrópolis, RJ: Vozes, 1999. 